\title{
Ethical Reflection Laden by Scientific Value
}

\author{
Xiang Xiaojun \\ College of Marxism, Wuhan University of Technology, Wuhan, China
}

Email address:

xxjflint@aliyun.com

\section{To cite this article:}

Xiang Xiaojun. Ethical Reflection Laden by Scientific Value. Humanities and Social Sciences. Vol. 3, No. 5, 2015, pp. $261-265$. doi: 10.11648/j.hss.20150305.25

\begin{abstract}
This article from the dialectical relationship between the freedom of scientific research and the constraint of ethic and moral, the two basic ethical principles of the scientific activities, reflected ethically on the load of science value, considered that the scientists should bear ethical and moral responsibility to a degree, and called for strengthening communication among the Government, scientists, and ordinary people.
\end{abstract}

Keywords: Science, Load of Value, Ethical Reflection

\section{Introduction}

Appearance of revolutionary technologies that may exert profound influence on human society will usually bring about huge panic in ethics; however, if people absolutely forbid these new technologies, they will probably lose many new opportunities that bring great benefits to humankind and even lag behind new development tendencies. How to seek a balance between the two? This paper is going to conduct analysis and discussion about relationship between scientific research and ethics and morals in the following aspects.

\section{Dialectical Relationship Between Freedom of Scientific Research and Restriction of Ethics}

Jonas has put forward a doubt "freedom of scientific research: is whatever can be done allowed?" Scientific research is a steamship and ethic is the beacon. Without "convoy" of ethics, the steamship of scientific research will be exposed to risks of getting lost and sinking. It can't be denied that freedom of scientific research is an cardinal principle that promotes scientific development and it needs maintenance and conformity. Science, a cause with high originality, provides society with unprecedented intellectual product--scientific knowledge. Here, only creating new knowledge is meaningful while idiomatic methods like duplication and imitation is meaningless in production of scientific knowledge. In order to promote academic prosperity and scientific development, scientific community must guarantee freedom of academic research of scientists and respect their spirit of innovation. This has been introduced into constitutions of civilized countries. Academic freedom includes freedom of exploring truth without scruple, freedom of doubting and examining existing achievements, freedom of conducting an academic research on interested subject, freedom of teaching or delivering academic opinions in public, freedom of academic criticism and counter-criticism and freedom of requiring to exclude interference and governance of all kinds of authorities within and outside academic circles, etc. Academic freedom is life of scientific research and the patron saint of academic prosperity. All scientific communities takes guaranteeing academic freedom as their duty-bound responsibility and sacred mission. However, just as any freedom is not absolute, freedom of scientific research doesn't mean that science is above all and that science can do anything it wants without reflecting on the consequences. As modern scientific research needs joint labor of tremendous scientific communities, accompanied by enormous material consumption, and blind utility of scientific achievements will result in irretrievable losses, under these situations, restriction must be above research freedom. The primary purpose of science is to benefit human beings, and principles of freedom of scientific research must be subject to this primary purpose of science. Necessary and appropriate ethical norms are not trying to hinder scientific research but "convoying" scientific development and making science head toward the direction that is beneficial to survival and happiness of human being.

"There is a common circumstance: appearance of revolutionary technologies that may have a far-reaching influence on human society always bring huge ethical panics; 
but if people absolutely forbid these new technologies, they will lose many new opportunities that will probably bring great benefits for human beings and even miss the opportunities for new development." [1] How to seek an equilibrium between the two? Are freedom of scientific research and moral rules are incompatible as fire and water and sharply conflicting? "International Conference on Recombination of DNA Molecules" held in February of 1975 formulated several principles for genetic research. Over 20-year practice has sufficiently indicated that necessary and appropriate moral rules haven't deviated from freedom principle of scientific research or hinder scientific development, but have promoted smooth scientific development. After a consensus is reached and norms are established, genetic recombination experiment has been launched in a better way and molecular biology has obtained a series of major achievements that are obvious to all. Freedom principle of scientific research also aims at promoting smooth scientific development and better benefiting human beings, but not on the contrary. Hence, moral rules and freedom of scientific research are not mutually exclusive but uniform, both of them are making a better life for human beings. When it comes to human cloning, some scientists have raised the flag of freedom of scientific research and opposed any restriction on human cloning research; some people believe that restriction on human cloning research is a modern version of "Copernicus Tragedy". Some scientists think that moral rules only involve application of achievements in scientific research but have nothing to do with scientific research itself, so scientific research itself should not be restricted. Although human cloning can be done technologically, it can't be done morally, there must be moral restrictions on it, and this is being highly responsible for human destiny. Before "Dolly" was born, scientists had gone through hundreds of experiments to cultivate a healthy cloned sheep. If human cloning experiment is unconditionally conducted under the circumstances that cloning technology is still not complete, there will probably be hundreds of the handicapped and freaks. In this way, it seems that freedom principle of scientific research is maintained, but in fact, it has harmed safety and respect of people and deviated from primary purpose of science. Hence, science should attach importance to value of morals and be restrained and guided by moral rules.

In fact, freedom of scientific research and restriction of ethics are a pair of contradictions in co-construction status, and the relationship between the two should be dialectical and unified. So-called co-construction status means that the two are not in a drastic confrontation, that's to say, result of development of two contradictory parties or contradictory unity is not elimination one party or perishing together, but mutual restriction and improvement of the two parties. The two contradictory parties not only provide opposite party with developmental motivation and condition with its own development, in the meantime, they put forward requirements to the opposite party based on requirements of its own development, thus presenting a reliance on development of the opposite party. Freedom of scientific research and restriction of ethics are right a pair of such contradictions, as they jointly push human beings from obscuration to enlightenment, from barbarism to civilization, from backwardness to progress, and from weakness to mightiness. Scientific research enriches truth factors and carve new morals for ethics, while ethics provide science \& technology with value orientations and intellectual impetus.

\section{Two Major Fundamental Ethical Principles of Scientific Activities}

Objective fairness of scientific activities emphasizes that scientific activities should exclude prejudices and avoid injustice, which is not only a requirement of cognition progress but also that of humanism. Objective fairness, as basic principle of scientific activities, reflects inherent unity of science and ethics. If what objectivity emphasizes on is to guarantee authenticity of faith in cognition process, then objective fairness, based on this, further highlights fairness of behaviors of people involved in scientific activities. This principle requires that, in the research process, researchers should maintain objective and fair, making research risks get shared fairly and reasonably; after research results have formed, researchers should prudently issue, propagandize, promote and apply them, trying their best to avoid unfair consequences. All in all, researchers should not only be responsible for objective authenticity of knowledge and faith but also be responsible for right propagation and fair utility of these knowledge and faith.

Priority principle of public benefits is another basic principle of scientific activities. The starting point of this principle is: science should be a cause that promotes sustainability of public welfare and living environment of human beings, and meet requirements of sustainable development. So-called "sustainable development" means "a development not only satisfying demand of contemporary people but also not constituting any harm to ability of meeting demand of future generations." [2] Any scientific activity that seriously harms public welfare of contemporary people and future generations as well as sustainability of the environment is immoral. This principle is the highest principle that conducts an ethical screening of all kinds of behaviors in scientific activities. Based on this principle, a temporary or permanent "prohibition" can be issued to any research. In turn, this principle can also be used to reflect and set rationality of some "forbidden zones".

According to priority principle of public benefits, in scientific researches, scientists should firstly be responsible for public benefits that may be influenced by an individual in the research (like the person accepting the experiment) and application of research achievements. If take the scientific worker as the first party, and the employer (university, enterprise, research institution, etc.) of the scientific worker as the second party, then these individuals and the public can be called the third party, and benefits of the third party should be prior to the second party, at the least benefits of the third party 
should not be harmed for benefits of the first two parties. Hence, firstly, scientific workers should objectively, fairly and comprehensively propagate relevant knowledge to relevant individuals and the public to guarantee their rights to know and equip them with abilities in actually participating in decision-making. Secondly, restriction that conforms to public benefits should be made on monopoly of knowledge to prevent interest groups like enterprise from using investment to control scientific research and exclusively enjoy the common resource--research achievements. Thirdly, when purposes of the second party or other researchers seriously harm benefits of relevant individuals and the public, scientific researchers have the obligation to give a caution to relevant people and even the whole society.

If we consider science as a social cause that creates, propagates and utilizes confirmed knowledge for public welfare, the two basic principles--objective fairness and priority of public benefits should be a kind of inherent restraint in scientific activities. For people who take science as their occupation, the two principles should be an essence of ethical codes of all kinds of scientific occupations, and present spiritual substance of scientific occupations. In occupation training of scientific workers, comprehending the two principles is indispensable. And what is worth being further pointed out is that this comprehending process should be accompanied by continuous enrichment and deepening of research experience of scientific workers. Combined with practice, this comprehending process will be internalized as an important organic constituent of their professional quality. In this way, the two principles can structure an open standardized framework that considers organizational systematization of science and objective of the whole society. The establishment of this framework declare significantly and publicly intrinsic consistency of science and ethics.

\section{Responsibilities of Scientists}

There are two implications for responsibilities of scientists: one is matters within their duties, namely, as a common social citizen, a scientist must conform to code of professional ethics of this industry when working on scientific research, we call it intrinsic responsibilities of scientists and it reflects academic attitudes that they should have; second is that scientists starts with realizing moral requirements in science and technology put forward by the outside world. This is a kind of ethical scope that explains to scientists that they should be responsible for attitudes they take towards others, collective and society and achieved consequences, we call it external responsibility of scientists which is a kind of special responsibility that scientists should take, reflects deep concern of scientists for human destiny and indicates their responsible attitude towards the whole society, it is also called social responsibility of scientists. Responsibilities stated in this paper involve external responsibilities more, while moral responsibilities of scientists commonly stated by people mainly refer to external responsibilities. However, as all kinds of behaviors that seriously violate criterion of scientific activities occur in the current scientific community, intrinsic responsibilities also can not be ignored. Hence, "scientific and technological workers can't forget their own professional ethics (intrinsic responsibilities), neither can they forget their own external responsibilities. That's to say, they can't forget enormous social responsibilities, neither they can neglect existence of scientific and technological ethics." [3]

Arguments in scientific values usually neglect responsibilities as subjects of scientific activities--scientists. From the perspective of science itself, modern science has become a social cause, and scientists generally belong to members or employees of some institution or organization, and they must consider social consequences of science and social ethical responsibilities of themselves. Zieman believes that "modern scientific research has been closely related with other social processes more, scientists are no longer outsiders of the society or be allowed to indulge themselves in their own fondness and to act as what they want." [4] While Arguments in scientific values have frequently become shields for scientists to evade social ethical responsibilities, consequently, scientists blame negative effects of science on subjective intentions of users of science. Although some harms brought to society by science are caused by misuse of users, scientists still have compelling obligations. Because rapid development and broad application of modern scientific knowledge are usually promoted by development of political power and commercial greediness, the risks of science are becoming greater and greater. Potential implication of scientific achievements is not what users of science can completely know about. As people with professional skills and knowledge, scientists can foresee application prospect of these knowledge and social risks that can be generated more accurately and comprehensively. Hence, scientists have the responsibility to try their best to objectively, fairly and responsibly conduct a forecast evaluation of possible positive and negative influences of their own research projects, and to implement scientific propagation and education among the public. However, arguments in scientific values usually make some scientists lose their former objectiveness and fairness in the face of conflicts of interest, and lose humanism when considering personal interests, which gives rise to misuse of science. Huxley says, "you don't know anything about intrigues in the damn scientific circle. I am worried that science will not be purer than any other field of human activities, though it should have been so. It's meaningless only with true level, it can't take effect until it relies on stunt and sophisticated background." [5] Although scientists are faced with great plights in maintaining their responsibilities as scientists, such as unpredictability of fundamental researches, survival of scientists themselves, unable personal defiance, etc. However, these are not reasons for drifting away from moral rules, when local, present, direct and temporary interests of government, group or enterprises conflict with fundamental, long-range and social \& natural overall interests, scientists should select the latter without any doubt. Professor Yang Zhenning has pointed out that "value judgment of scientific researches can't be separated from that of society, 
fundamental and ultimate value judgment will not depend on science for science but $\mathrm{n}$ whether science is beneficial for human beings". [6] If scientists can't realize this point or keep away from inhumane usage of scientific research achievements, they will probably make their own fruits of labor become tools of some inhumane power and harm the whole mankind. Different evaluations of Harper--German Chemist are just worth pondering. As a chemist, he was the first one who compounded chemical fertilizers and made outstanding contributions to getting rid of hunger for human beings, and he honorably won Nobel Prize in Chemistry in 1918 because of this achievement; As "father of chemical warfare", he initiated a large-scale chemical warfare in World War I for Germany, making tens of thousands of people die in pain or be disable in their lifetime, so he was a major war criminal and was called "demon of warfare". American scholar--Deschatin pointed out that "just as all tools, application of science relies on values and application purposes of users. While the examination of these values and application purposes should be done before but not after application of this tool." [7]

At the present times, science $\&$ technology has a bearing on destiny of a nation and future of human beings. From basic meaning, it is no longer a personal matter of scientific workers but a cause of a country and nation and a common cause for the whole mankind. In order to guarantee normal proceeding of scientific research activities and better serve benefits of country, nation and human beings, scientific communities and scientific research institutions of not a few countries have put forward many moral requirements to scientists and made specific regulations in ways of laws, charters or declarations. For example, as early as 1948, Chapter of Scientists passed by World Federation of Scientific Workers made 12 regulations about responsibilities of individual scientists or groups for science, society and world, and there were 4 regulations about scientific responsibilities: “(1) Maintain soundness of scientific research and resist suppression and distortion of scientific knowledge. (2) Make all scientific achievements public. (3) Step over obstacles of race and even nationality and cooperate with other scientists. (4) Properly consider balance between basic science and applied science to guarantee development of science." In 1949, Chapter of Scientist passed in the fifth conference of International Council of Scientific Unions also made 9 regulations about responsibilities and obligations of scientists, for example, scientists "should keep spirits of honesty, nobility and cooperation", "need to realize working objective when being employed and figure out significance of morality and justice", "prevent misuse of science", "emphasize on and develop humanistic value that science \& technology has", although "have the right to make achievements of researches that they work on public", "except those achievements that need to be restricted out of social or ethical just causes". At present, these regulations are still being further modified and perfected and have been carefully executed by most scientists and scholars.

For individuals of scientific researchers, there can completely be many kinds of motives of devoting themselves to science. Just as Einstein said, "there are many houses in the temple of science, and there are all kinds of people living in them, and there are different motives of guiding them somewhere". [8] Einstein, from the angle of value concern, has divided scientists into three types: joyful intelligence type, utilitarian type and ultimate concern type. Although joyful intelligence type and utilitarian type scientists can make great contributions to scientific development and progress of scientific undertakings, the main impetus of scientific progress doesn't derive from them but from scientists who take ultimate concern as value goal. What joyful intelligence type scientists pursue is to obtain "vivid and vigorous experience as well as satisfaction of ambitions" from scientific exploration activities. Utilitarian scientists take realizing utilities as their direct goal, they work on scientific activities by depending on utilities and social environment, utilitarian goals doesn't always accompany science. Only ultimate concern type scientists can enduringly work on scientific activities, out of respect and appreciation of universe order and with a kind of "universe religious affection", they pursue to draw a simplified world picture that is easily comprehended with the most appropriate method. Exploring profound mystery of the world and concerning human destiny are boundless. Einstein said, "there is a huge world beyond us, and it's like a great and everlasting myth, but there is at the least a part of it that can be reached by observation and thought. Staring at and thinking profoundly the world is attracting us like obtaining liberation, and we can find inner freedom and tranquility while concentrating on this cause. [9] Although motives are different, only if they work on scientific researches by respecting reality, being in strict accordance with scientific methods and procedures and abiding by common criteria of scientific community, they can make contributions and even great contributions and win a place in the temple of science. Of course, we must also admit that only people who consistently seeking the truth can be scientists in a real sense. However, if they make other purposes especially utilitarian values outmatch truth-seeking value, they can probably be black sheep in the field of science, there is no exception for people who have won Nobel prizes.

\section{Conclusion}

In conclusion, freedom of scientific research and restriction of ethics and morals are a pair of contradictions in co-construction state, and the relationship between the two is dialectical. As basic principle of scientific activities, objective fairness reflects intrinsic uniformity of science and ethics. Priority principle of public benefits is another basic principle of scientific activities. The two principles declare publicly the intrinsic uniformity of science and ethics.

\section{References}

[1] Yu Liangyun: Value-Laden of Science and Its Construction Principle of Ethics, loaded in Scientific \& Technological Progress and Countermeasures in the $12^{\text {th }}$ journal, 2001. 
[2] World Commission on Environment and Development: Our Common Future, Beijing, 1989 version of World Affairs Press, page 19 .

[3] Gan Shaoping: Scientific and Technological Ethics: A Controversial Subject, loaded in Philosophical Trends in the 9th journal, 2000.

[4] Qi Man: An Introduction to the Metascience, Changsha, 1998 version of Hunan People's Publishing House, page 310-311.

[5] Braude: People Who Betrays Truth--Fraud in Scientific Circle, Beijing, 1988 version of Science Press, page 24.

[6] Liu Dachun: Btween Truth and Kindness--Ethical Issues and Moral Choices in Era of Science and Technology, Beijing, China Social Sciences Publishing House, 2000 version, page 123.
[7] R. Joseph Des Jardins. Environmental Ethics. Belmont: Wads worth Publishing Company. 1993.

[8] Collected Works of Alberteinstein (Volume 1), Beijing, 1979 version of The Commercial Press, page 100.

[9] Collected Works of Alberteinstein (Volume 1), Beijing, 1979 version of The Commercial Press, page 2.

[10] Liu Dachun: Btween Truth and Kindness--Ethical Issues and Moral Choices in Era of Science and Technology, Beijing, China Social Sciences Publishing House, 2000 version, page 39. 